\title{
Thermochemistry of Heteroatomic Compounds: the Heats of Combustion and Formation of Glycoside and Adenosine Phosphates
}

\author{
Vitaly Ovchinnikov, Ludmila Lapteva \\ National Researching University, Tupolev Kazan State Technical University, Kazan, Russian Federation \\ E-mail:chem_vvo@mail.ru \\ Received April 22, 2011; revised June 2, 2011; accepted July 13, 2011
}

\begin{abstract}
The heats of combustion of 4-th glycoside in the condensed state with the use of the equation $\Delta_{\text {comb }} H=15.7-117.2(N-g)$, in which $N$ is a number bond-forming (valence) electrons less the number $(g)$ of lone electron pairs of nitrogen $(g=1)$ and oxygen $(g=2)$, have been determined. Such dependence is deduced previously joint for the description of the combustion enthalpies of 17 simple ethers of a cyclic structure and different sugars. The heats of formation $\left(\Delta_{f} H^{\circ}\right)$ of the mentioned above glycosides were calculated according to the Hess law via two ways: 1$)$ through the use their heats of hydrolysis $\left(\Delta_{h y d r} H\right)$, which have been investigated earlier experimentally, 2) with the use the calculated the heats of combustion. The last procedure has been used also for the calculation of the heats of formation of the adenosine tri(ATP)-, di(ADP)and mono(AMP)phosphates because of such thermochemical parameter is often hard achieved experimentally. The heats of hydrolysis $\left(\Delta_{f} H_{h v d r}^{\circ}\right.$ ) of ATP into ADP and ADP into AMP were calculated on the basis of their heats of formation in water $\left(\Delta_{f} H_{a q}^{\circ}\right)$. The free energies of the same process $\left(\Delta_{h y d r} G\right)$ were known in literature. Last circumstance give us a possibility to calculate the hydrolysis entropies $\left(\Delta_{\text {hydr }} S\right)$ using the Gibbs equation. The entropy values are a large negative, that pointed on the preliminary complex formation between adenosine phosphates and water before the breaking of $\mathrm{P}-\mathrm{O}$ bonds or P-O-C fragments in its.
\end{abstract}

Keywords: Glycoside Phosphates, Adenosine Phosphates, Heat of Combustion, Heat of Formation

\section{Introduction}

Molecules, which contain cyclic phosphoric fragments, represent the big interest within many decades as a biochemical objects $[1,2]$. Nucleosides and phosphates of sugars are representative of the important classes of esters of a phosphorous acid. However their thermochemistry, having essential value for the much deeper, detailed understanding of their important biochemical function, is poorly investigated. For this reason we have undertaken the theoretical calculation of the heats of combustion $\left(\Delta_{\text {comb }} H\right)$ and then on this basis the heats of formation $\left(\Delta_{f} H^{\circ}\right)$ in the condensed state of organic phosphor-nucleotides of a cyclic structure, kinetics and thermochemistry of hydrolysis of which has been investigated earlier experimentally [3].

\section{Results and Dicussions}

The heats of hydrolysis $\left(\Delta_{h y d r} H\right)$ of methyl- $\alpha$-D-glycopyranoside-4',6'-cyclophosphate (1), methyl- $\beta$-D-ribofuranoside-3',5'-cyclo-phosphate (2), adenosine(Ade)-3',5'mono-cyclophosphate(3), adenosine-2',3'-mono- cyc-lophosphate (4) were founded previously (Table 1) [3]. The products of these interactions with water are methyl$\alpha$-D-glucopyranoside (5,aq), methyl- $\beta$-D-ribofuranoside $(6, a q)$ and 1-adenosine ribofuranoside (7,aq) are presented in Equation (1)

$$
\begin{aligned}
& (\mathbf{1 - 4}, l i q)+2 \mathrm{H}_{2} \mathrm{O}(\mathrm{liq}) \\
& \rightarrow(\mathbf{5 - 7}, a q)+\mathrm{H}_{3} \mathrm{PO}_{4}(a q)+\Delta_{\text {hydr }} H
\end{aligned}
$$

To calculate the heats of formation $\left(\Delta_{f} H^{\circ}\right)$ of the molecules (1-4) and glycosides (5-7) in condensed state 
and in water environment $\left(\Delta_{f} H_{a q}^{\mathrm{o}}\right.$ ), necessary to calculate at first their heats of combustion $\left(\Delta_{\text {comb }} H\right)$. The sum of lasts with the heats in the water shells $\left(\Delta_{w s} H\right)$, which were calculated via the molecular mechanics method ( $M M M$, column 7 in Table 1), gives the magnitudes of $\Delta_{f} H^{\circ}$ iq in Equation (2)

$$
\Delta_{f} H_{a q}^{\circ}(5-7)=\Delta_{f} H^{\circ}+\Delta_{w s} H
$$

In the previous communication us it has been estab- lished, that the heats of formation $\left(\Delta_{f} H^{\circ}\right)$ of some phosphorylated sugars can be calculated effectively from their heats of of combustion $\left(\Delta_{\text {comb }} H\right)$, which generally depends on the number of bond-forming (valent) electrons $N$ in a molecule minus the number $(g)$ of lone electron pairs of nitrogen $(g=1)$ and oxygen $(g=2)$ in Equations (3) and (4) [5]

$$
\Delta_{\text {comb }} H=15.7-117.2(N-g)
$$

Table 1. Thermochemical parameters $\left(\mathrm{kJ} \cdot \mathrm{mol}^{-1}\right)$ of glycoside and adenosine phosphates. P: 101kPa; T: 298.15; all compounds are in condensed state.

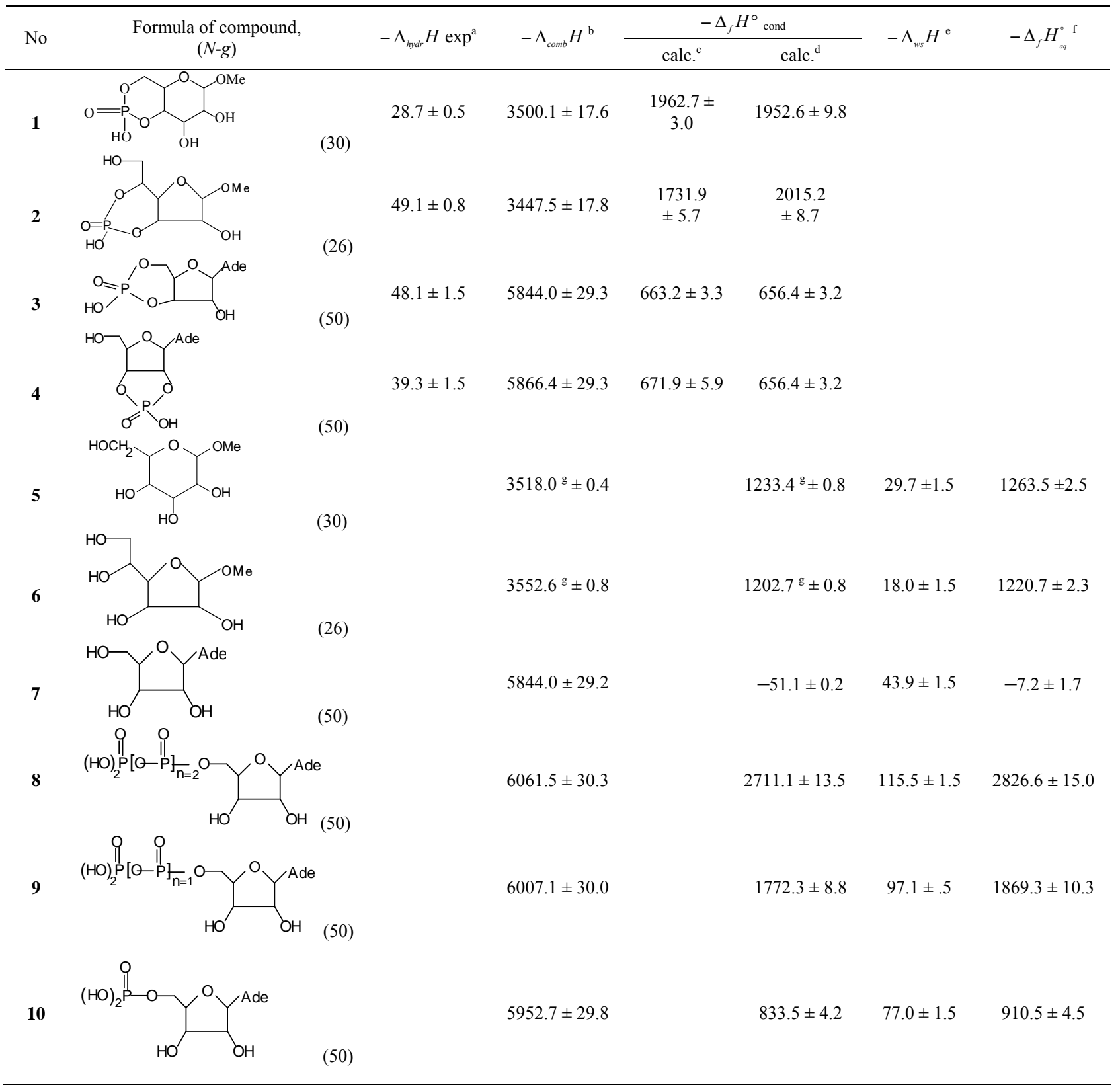

${ }^{\mathrm{a}}$ Data of the Ref. [3]; ${ }^{\mathrm{b}}$ Calculated by Equation (3); ${ }^{\mathrm{c}}$ Calculated by Equations (1) and (5); ${ }^{\mathrm{d}}$ Calculated by Equations (3) and (5); ${ }^{\mathrm{e}} \mathrm{Calculated}$ by MMM-method; ${ }^{\mathrm{f}}$ Calculated by Equation (2); ${ }^{\mathrm{g}}$ Data of the Reference [6]. 


$$
\begin{aligned}
& \mathrm{C}_{p} \mathrm{H}_{q} \mathrm{O}_{r} \mathrm{~N}_{s} \mathrm{P}_{t}(\text { condens })+\mathrm{O}_{2} \rightarrow \\
& u \mathrm{~N}_{2}(\text { gas })+x \mathrm{CO}_{2}(\text { gas }) \\
& +y \mathrm{H}_{2} \mathrm{O}(\text { liq })+z \mathrm{H}_{3} \mathrm{PO}_{4}(\mathrm{sol})+\Delta_{\text {comb }} H
\end{aligned}
$$

where $p, q, r, s, t, u, x, y, z$ are stoichiometric factors. This approach was applied to all biomolecules (1-7) and the calculated $\Delta_{c o m b} H, \Delta_{f} H^{\circ}$ and $\Delta_{f} H^{\circ}$ magnitudes through combination of the Equations (1-5) presented in Table 1.

$$
\Delta_{\text {hydr } / \text { comb }} H=\sum\left(\Delta_{f} H^{\circ}\right)_{\text {prod }}-\sum\left(\Delta_{f} H^{\circ}\right)_{\text {reag }}
$$

Necessary values $\Delta_{f} H^{\circ}\left(\mathrm{kJ} \cdot \mathrm{mol}^{-1}\right)$ for $\mathrm{CO}_{2}$ (gas): -395.5, $\mathrm{H}_{2} \mathrm{O}(\mathrm{liq})$ : -285.8 and $\mathrm{H}_{3} \mathrm{PO}_{4}(\mathrm{aq}, \mathrm{sol}):-1289.9$, -1279.0 are taken from the monograph [4].

If it can be seen from the data of Table 1, the calculated the heats of formation in the condensed state with the use of the experimental heats of hydrolysis [3] and the same values obtained via Equations (3)-(5) [5] are good correspond each other in the range of the assumed in Table 1 (columns 5,6) indefinites 2\% - 3\%, which expressed in Equation (6)

$$
\begin{gathered}
\Delta_{h y d r} H\left(\mathrm{~kJ} \cdot \mathrm{mol}^{-1}\right)=(-90.9 \pm 159.3) \\
+(0.9 \pm 1.1) \Delta_{\text {calc }} H\left(\mathrm{~kJ} \cdot \mathrm{mol}^{-1}\right) \\
r=0.985, s_{o}=143.2, n=4
\end{gathered}
$$

It gives a real basis for the application of the mentioned above approach to the calculation of the thermochemical parameters of such important bioorganic substances as adenosine tri(ATP, 8)-, $\operatorname{di}(\mathrm{ADP}, 9)-$ and mono(AMP, 10) phosphates.

It is known $[1,2]$, that at each step of the hydrolysis reaction of adenosine phosphates in the water shell, as it shown on Equations (7)-(9), the essential quantity of energy due to the breaking of P-O bonds in P-O-P fragments is allocated accordingly to Hess law in Equation (5).

$$
\begin{aligned}
\Delta_{h y d r} H= & {\left[\Delta_{f} H^{\circ}(\mathbf{8}, a q)+\Delta_{f} H^{\circ}\left(H_{3} P O_{4}, a q\right)\right] } \\
& -\left[\Delta_{f} H^{\circ}(\mathbf{9}, a q)+\Delta_{f} H^{\circ}\left(H_{2} O, l i q\right)\right] \\
\Delta_{h y d r} H= & {\left[\Delta_{f} H^{\circ}(\mathbf{9}, a q)+\Delta_{f} H^{\circ}\left(H_{3} P O_{4}, a q\right)\right] } \\
& -\left[\Delta_{f} H^{\circ}(\mathbf{1 0}, a q)+\Delta_{f} H^{\circ}\left(H_{2} O, l i q\right)\right] \\
\Delta_{h y d r} H= & {\left[\Delta_{f} H^{\circ}(\mathbf{1 0}, a q)+\Delta_{f} H^{\circ}\left(H_{3} P O_{4}, a q\right)\right] } \\
& -\left[\Delta_{f} H^{\circ}(\mathbf{7}, a q)+\Delta_{f} H^{\circ}\left(H_{2} O, l i q\right)\right]
\end{aligned}
$$

In last Equation (9) the dissociation to the same bond in AMP leads to formation of a water 1-adenosine ribofuranoside (7) and a water phosphorus acid. It is necessary to note, that into the structure of a listed adenosine phosphates enter the some hydroxyl groups at phosphorus, the energy of each is estimated as $-54.4 \mathrm{~kJ} \cdot \mathrm{mol}^{-1}$; this factor is considered at calculations of $\Delta_{\text {comb }} H$ for compounds (8-10).

Despite of the approached calculations of the last thermochemical parameter, it is possible to note, that the hydrolysis of ATP and ADP is carried out with identical (about $-45,-46 \mathrm{~kJ} \cdot \mathrm{mol}^{-1}$ ) energy while the hydrolysis AMP up to adenosine furanoside (7) and a phosphorus acid is characterized noticeably by more greater the heats of about $-86 \mathrm{~kJ} \mathrm{~mol}^{-1}$, which presented in Table 2. Taking into account the published in the monograph [1] the free energies of hydrolysis $\left(\Delta_{h y d r} G\right.$ ) for ATP, ADP and AMP and obtained in this work $\Delta_{h y d r} H$ magnitudes, the values of the entropies ( $\Delta_{h y d r} S$ ) according to the Gibbs Equation (10) were calculated and shown in Table 2.

$$
\Delta_{h y d r} G=\Delta_{h y d r} H-T \cdot \Delta_{h y d r} S
$$

Necessary to note, that the calculated the entropy magnitudes are a large negative, especially for the hydrolysis process of AMP, that can pointed on the preliminary complex formation between AMP and a water molecules before the breaking of $\mathrm{P}-\mathrm{O}$ bond in $\mathrm{P}-\mathrm{O}-\mathrm{C}$ fragment.

\section{Conclusions}

Thus, as it has been shown during this work the Equation (3), worked up to the correlation between of the heats of combustion of 17 sugars of the different space structure and the number of the valent electrons in its, excluding of the lone electron pairs of heteroatoms, can be useful applied to the calculation of the same thermochemical parameters of the different bioorganic molecules, in partly glycosides and adenosine phosphates.

Table 2. Thermodynamic parameters $\left(\mathrm{J} \cdot \mathrm{mol}^{-1}\right.$ and $\mathrm{J} \cdot \mathrm{mol}^{-1} \cdot \mathrm{K}^{-1}$ ) of the hydrolysis reaction of adenosine phosphates at $298.15 \mathrm{~K}$.

\begin{tabular}{cccc}
\hline Hydrolysis reaction & $-\Delta_{\text {hydr }} G^{\mathrm{a}}$ & $-\Delta_{\text {hydr }} H$ & $-\Delta_{\text {hydr }} S$ \\
\hline Equation (7) & 30543.2 & 46800 & 54.5 \\
& & & \\
Equation (8) & 27196.0 & 45300 & 60.7 \\
& & & \\
Equation (9) & 9204.8 & 86400 & 259.0 \\
\hline
\end{tabular}

${ }^{\mathrm{a}}$ Data of the Reference [1]. 


\section{References}

[1] D. E. C. Corbribge, "Phosphorus: An Outline of Its Chemistry, Biochemistry, and Technology," 2nd Edition, Elsevier, Amsterdam-Oxford-New York, 1980.

[2] A. White, Ph. Handler, E. Smith, R. Hill and I. R. Leman, "Principles of Biochemistry," McGraw-Hill, New York, 1978.

[3] J. A. Gerlt, F. H. Westheimer and J. M. Sturtevant, "The Enthalpies of Hydrolysis of Acyclic, Monocyclic, and Glycoside Cyclic Phosphate Diesters," The Journal of Biological Chemistry, Vol. 250, 1975, pp. 5059-5067.
[4] J. D. Cox and G. Pilcher, "Thermochemistry of Organic and Organometallic Compounds," Academic Press, New York, 1970.

[5] V. V. Ovchinnikov and N. R. Muzafarov, "ThermoChemistry of Heteroatomic Compounds. Calculation of the Formation Enthalpy for Methyl- $\alpha$-D-4',6'-CyclophosPhate on the Basis of His Enthalpy of Combustion," Russian Journal of Organic Chemistry, Vol. 45, No. 1, 2009, pp. 318-319.

[6] S. M. Skuratov, A. A. Strepikheev and M. P. Kozina, "About the Combustion of Five and Six-Membered Heterocyclic Compounds," Dokl. Acad. Sci. SSSR, Vol. 117, 1957, pp. 452-454. 